\title{
Unique features of the Mediterranean food environment: Implications for the prevention of chronic diseases Rh: Mediterranean food environments
}

\author{
Julia Díez ${ }^{1} \cdot$ Usama Bilal $^{1,2} \cdot$ Manuel Franco ${ }^{1,3}$
}

Published online: 28 November 2018

(C) Springer Nature Limited 2018

\section{Introduction}

The rising obesity pandemic is a public health priority worldwide [1]. Obesity is associated with an increased risk for non-communicable diseases (NCDs), including diabetes, cardiovascular disease and cancer [1]. In Spain, the prevalence of obesity in adults nearly doubled between 1987 (8.0\%) and $2012(16.5 \%)$ [2]. Historically, strategies to prevent obesity have targeted high-risk individuals, showing poor results or lack of improved outcomes [3]. Therefore, it is essential to shift paradigms around the causes of obesity towards a socio-ecological perspective, in which individual dietary behaviors are embedded within broader contextual determinants [3, 4].

At the population level, diet is driven by upstream determinants including food availability, food accessibility and food affordability, which in turn are influenced by agriculture and production policies, marketing and media, urbanization, or culture and social norms $[4,5]$. These population diet determinants differ between countries and cultures [6] and have changed over time [7]. These changes have transformed dietary patterns of Mediterranean countries (e.g. Greece), traditionally adhered to Mediterranean diets (high in legumes, fruits and vegetables, and whole grains), which are gradually moving towards a

Manuel Franco

manuel.franco@uah.es

1 Social and Cardiovascular Epidemiology Research Group, School of Medicine, Universidad de Alcalá, Alcalá de Henares, Madrid, Spain

2 Urban Health Collaborative, Drexel Dornsife School of Public Health, Philadelphia, PA, United States

3 Department of Epidemiology, Johns Hopkins Bloomberg School of Public Health, Baltimore, MD, United States
'Westernised/Americanised' diet [8]. In conclusion, during the last decades demographic, economic and social changes have changed traditional food patterns into Western food patterns [1].

Although these urbanization and economic processes are rapidly changing the food supply and distribution systems, many cultural and social differences still exist between the U.S and Southern-European countries (e.g. Spain) regarding the shape and distribution of the food environment $[6,9]$. Despite a growing literature on the influence of different aspects of the food environment on diet in Anglo-Saxon countries, there is little evidence for Mediterranean urban settings [9]. Comprehensive monitoring of the characteristics of Mediterranean food environments related to obesity and NCDs is needed to allow comparisons, and to timely evaluate the impact of initiatives to improve food environments [10].

In this context, the 'Heart Healthy Hoods' project (www. hhhproject.eu) is an ongoing study, which studies the association between urban environment characteristics (including the food environment) and cardiovascular outcomes in Madrid, as an example of a Southern-European city $[3,11]$. This Perspective article reviews the unique characteristics of Mediterranean food environments highlighting current gaps in the literature, which might help promoting healthier diets and preventing chronic diseases.

\section{Unique characteristics of Mediterranean food environments}

Assessing the retail food environment, the retailing part of a food system, involves measuring: 1) the community food environment (number, type and location of food outlets); and 2) the consumer nutrition environment (in-store characteristics, such as prices, promotions, or nutritional quality) [5]. We argue that Mediterranean cities have a unique food 
Fig. 1 Trends in the proportion of food stores by type from 2012 to 2017 in the city of Madrid, Spain. City of Madrid data was used with permission from Ayuntamiento de Madrid: Datos Abiertos. 2018. https://datos.ma drid.es/ Accessed February 1st, 2018

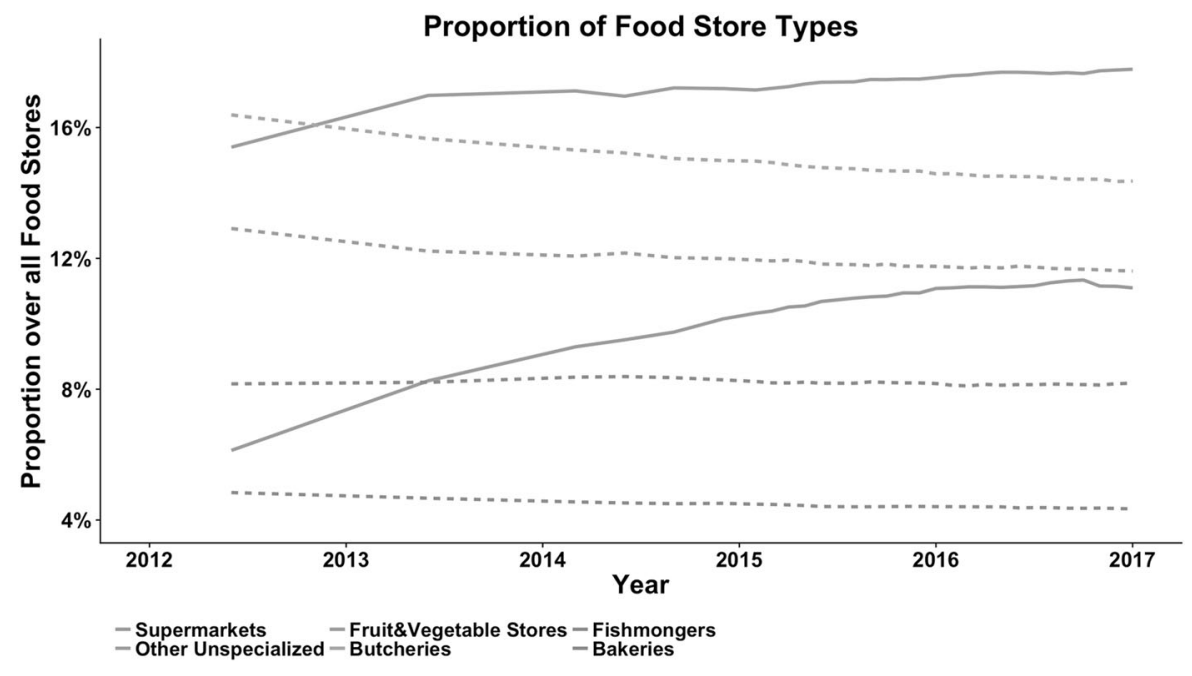

environment in terms of 1) diversity of types of stores, 2) compactness of urban form, and 3) a unique consumer food environment. What follows is a brief review of these three arguments and the consequences for measuring Mediterranean food environments.

\section{Diversity of food store types}

Traditionally, the market share concentration of food retailing activity in Mediterranean countries has been low, as compared to the U.S. and other Anglo-Saxon countries. Mediterranean food environments have a larger proportion of food markets and small specialized stores, as opposed to large retail chains of supermarkets or convenience stores [6, 12, 13]. These small specialized stores include fruit and vegetable store, fishmongers and butchers. Yet, few studies have assessed the role of these specialized food stores as alternative healthy food sources. A previous study, conducted by Pettinger et al [13], highlighted the relevance of small specialized food stores for Mediterranean populations: whereas a larger proportion of English participants $(89.9 \%)$ used a supermarket at least once a week than those in France $(74.5 \%)$, preferring to buy everything 'under one roof', the French used bakers, butchers, fishmongers and fruit and vegetable stores more frequently. These specialized food stores are the primary healthy food source for residents in Madrid, who prefer the closer social relationships with food store owners and the trust that is built with them [14]. These findings occur at the same time that traditional stores are in decline (e.g. in Spain), while supermarkets are becoming dominant due to their competitive prices and wider choices [14, 15]. Moreover, these changes in the retail food environment have been found to vary by type of neighborhood social and economic change [16]. Fig. 1 shows the trends over the last 6 years (2012 to 2017) in the proportion of food stores of each type. As the figure shows, there's a monotonic increase in the proportion of supermarkets and other unspecialized stores, and a small decline in the proportion of all types of specialized stores.

Previous studies have suggested to improve availability of supermarkets as a specific strategy to improve healthy food availability [17]. However, labelling 'supermarkets' as healthy food sources, neglects the increased availability of cheaper, processed, higher fat, and added-sugar food options available in line supermarkets [17, 18]. In fact, research in Latin American countries has shown how supermarkets worsen population diets, and are rapidly becoming the main source of ultra-processed foods [19].

Moreover, we argue that preserving the diversity of Mediterranean urban food environments could be not only linked to adopting healthier dietary patterns, but also to social behaviors. As recognized in 2010 by UNESCO, the Mediterranean diet is an intangible cultural heritage, not only because of its nutritional aspects, but also for encompassing other aspects ('eating together' and 'socializing among others') [20]. A previous study examining residents' perspectives around their local food environment, showed that through grocery shopping, residents socialized with each other [15]. Participants of this study highlighted that these encounters (e.g. at the public market) served as a social protection net against loneliness, and as opportunity structures for socializing [15]. Food environments are a highly complex phenomenon resulting from the interaction between multiple physical and social influences [4, 12], not just healthy food availability of the presence of supermarkets.

Another notable feature of Mediterranean food environments illustrating their diversity are public markets. Defined as 'a group of locally owned, primarily private retail businesses leasing space in a shared facility with fresh foods and community services', these covered markets are 
open year-round. These markets, as farmers' markets do in the US, promote public health in multifaceted aspects: increasing the consumption of fresh foods (e.g. fruit and vegetable) [21], and reducing social isolation (e.g. promoting social interactions with the vendors, or with other customers or residents) $[11,15]$. Moreover, public markets represent public spaces characterized by their proximity, personal treatment, and urban architectural patrimony. Yet, the potential influence of markets on healthy food environments has not been fully recognized.

\section{Compactness of Mediterranean food environments}

Walkable environments are areas where there is increased availability of destinations (to walk to), a street network that is conducive to walking (with a high degree of connections), and with enough density to guarantee that destinations are not too far apart [22]. The reduced levels of urban sprawl of Mediterranean cities create more compact-retail environments and promote non-motorized (walking or bicycling) accessibility [22, 23].

Partially as a consequence of this increased compactness, the number of food stores per resident is three times higher in Spain, Italy, and Portugal than in the United Kingdom [12]. A study, conducted within the Heart Healthy Hoods project, compared local food environments in two different cultural cities: Madrid (Mediterranean food environment), and Baltimore (Americanized food environment) [6]. This study showed that $77 \%$ of the residents in Madrid lived within less than $200 \mathrm{~m}$ from a food store with high healthy food availability. However, 95\% of Baltimore's residents lived further than $400 \mathrm{~m}$ from these stores [6]. As shown in Table 1, the density of food stores was 3.5 times higher in Madrid than in Baltimore. Marquet et al. [23]. also highlighted the relevance of proximity for walking trips in the city of Barcelona. These results illustrate the need to preserve well-connected retail food environment in terms of diversity of food store types, which are also highly accessible by walking.

Table 1 Food store density in the cities of Madrid and Baltimore, 2016

\begin{tabular}{lll}
\hline City & $\begin{array}{l}\text { Madrid } \\
(\text { Spain) }\end{array}$ & $\begin{array}{l}\text { Baltimore (United } \\
\text { States) }\end{array}$ \\
\hline Total population (n) & 3141000 & 621000 \\
$\begin{array}{l}\text { Food outlets (n) } \\
\begin{array}{l}\text { Food outlet density (food } \\
\text { stores/1000 residents) }\end{array}\end{array}$ & 16367 & 1028 \\
\hline
\end{tabular}

${ }^{\mathrm{a}}$ Data available at datos.madrid.es for the city of Madrid.

${ }^{b}$ Data available at http://mdfoodsystemmap.org/ for the city of Baltimore

\section{Consumer food environment in the Mediterranean context}

The consumer food environment is assessed through the measurement of food prices and their nutritional quality [5, 10]. Subsequently, characterizing Mediterranean urban food environments requires assessing the actual foods that food stores offer, not just food store types or accessibility.

The 'Nutrition Environment Measurement Surveys in Stores' (NEMS-S), developed by Glanz et al, is one of the most widely observational measures used to assess the consumer food environment [24]. The NEMS-S measure, protocol and training are readily accessible online; and the instrument has shown a high inter-rater reliability, test-retest reliability, and face and criterion validity [24]. In brief, it measures the availability and cost of healthy options compared to less healthy options in food stores over 11 food groups (low-fat or skim milk, fresh fruit, fresh vegetables, lean ground beef, fat-free or reduced-fat hot dogs, reducedcalorie frozen dinners, low-fat baked goods, diet sodas and $100 \%$ fruit juices, whole-grain bread, baked chips, and lowsugar cereal), based on a mainstream American diet [24].

Therefore, within the Heart Healthy Hoods study, we adapted the original NEMS-S tool to assess Mediterranean consumer food environments. While previous researchers have modified the NEMS-S tool to other urban contexts, to the best of our knowledge, no equivalent adaptation exists for Mediterranean contexts [25]. The adapted NEMS-Med audit tool is depicted in Table 2, and available to readers under request. The NEMS-Med tool includes 11 food groups: 1) fruits; 2) vegetables; 3) nuts; 4) non-alcoholic beverages; 5) bread, cereals and baked goods; 6) milk, dairy products and eggs; 7) oil and butter; 8) rice and pasta; 9) legumes; 10) meat and meat products; and 11) fish (see Table 2). The scoring was based on the NEMS-S scoring protocol [24] and modified to accommodate the Mediterranean dietary pattern [20]. In future research, we will document the distribution of the consumer food environment in a Southern European city (Madrid), and its association with socioeconomic status and nutrition-related outcomes.

\section{Conclusions}

Understanding the economic, social and urban processes that have driven the change in traditional dietary patterns during the last decades is a key public health challenge. Mediterranean urban food environments present unique characteristics in terms of diversity and compactness, which can promote healthy food availability and accessibility.

Tackling the undergoing 'Westernization' of Mediterranean urban food environments requires valid and contextspecific measures to characterize the community and the 
Table 2 Food groups, food items, and variables assessed in the Mediterranean Environment Measure Survey in Stores (NEMS-Med)

\begin{tabular}{|c|c|c|c|}
\hline \multirow[b]{3}{*}{ Food group } & \multicolumn{3}{|l|}{ Variables } \\
\hline & \multirow[t]{2}{*}{$\underline{\text { Availability }}$} & \multicolumn{2}{|l|}{ Price } \\
\hline & & Absolute & Comparative \\
\hline 1) Fresh fruits & $\mathbf{X}$ & $\mathbf{X}$ & \\
\hline 2) Vegetables (fresh/frozen) & $\mathbf{X}$ & $\mathbf{X}$ & \\
\hline $\begin{array}{l}\text { 3) Nuts } \\
\text {-Raw versus processed }\end{array}$ & $\mathbf{X}$ & & \\
\hline $\begin{array}{l}\text { 4) Non-alcoholic beverages } \\
\text { - Fruit juice: } 100 \% \text { juice } \\
\text { versus juice drinks } \\
\text { - Soda: diet versus regular }\end{array}$ & $\mathbf{X}$ & & $\mathbf{X}$ \\
\hline 5) Bread: $100 \%$ whole grain & $\mathbf{X}$ & $\mathbf{X}$ & \\
\hline 6) Baked goods & $\mathbf{X}$ & & \\
\hline $\begin{array}{l}\text { 7) Cereals } \\
\text {-Plain versus }>7 \mathrm{~g} \text { of sugar } \\
\text { per serving } \\
\text {-White rice versus whole- } \\
\text { grain rice }\end{array}$ & $\mathbf{X}$ & & $\mathbf{X}$ \\
\hline $\begin{array}{l}\text { 8) Milk, dairy products and } \\
\text { eggs } \\
\text {-Skim/low-fat versus whole } \\
\text {-White cheese versus aged } \\
\text { cheese } \\
\text {-Low-fat yoghurts } \\
\text {-Eggs }\end{array}$ & $\mathbf{X}$ & & $\mathbf{X}$ \\
\hline $\begin{array}{l}\text { 9) Oil and butter } \\
\text { - Extra virgin olive oil versus } \\
\text { sunflower oil } \\
\text { - Butter versus light butter }\end{array}$ & $\mathbf{X}$ & & $\mathbf{X}$ \\
\hline 10) Legumes & $\mathbf{X}$ & & \\
\hline $\begin{array}{l}\text { 11) Meat and meat products } \\
\text { (red meat and poultry) } \\
\text { - Red meat versus poultry } \\
\text { - Processed meat }\end{array}$ & $\mathbf{X}$ & & $\mathbf{X}$ \\
\hline $\begin{array}{l}\text { 12) Fish } \\
\text { - Fresh fish } \\
\text { - Unprocessed seafood versus } \\
\text { processed seafood } \\
\text { - Tuna }\end{array}$ & $\mathbf{X}$ & $\mathbf{X}$ & \\
\hline
\end{tabular}

consumer food environments. Understanding and protecting Mediterranean food environments may also help preventing the 'Westernization' of the Mediterranean diet, improving population diets and reducing chronic diseases burden.

Acknowledgements This article is published as part of a supplement sponsored by the Mediterranean Diet Foundation and the Diputació de Barcelona.

Funding : Julia Díez and Manuel Franco were funded by the European Research Council under the European Union's Seventh Framework Programme (FP7/2007- 2013/ERC Starting Grant HeartHealthyHoods Agreement n.336893). Usama Bilal was funded by a Johns Hopkins Center for a Livable Future-Lerner Fellowship.

\section{Compliance with ethical standards}

Conflict of interest The authors declare that they have no conflict of interest.

\section{References}

1. Swinburn BA, Sacks G, Hall KD, McPherson K, Finegood DT, Moodie ML, et al. The global obesity pandemic: shaped by global drivers and local environments. Lancet (Lond, Engl). 2011;378:804-14.

2. Basterra-Gortari F, Bes-Rastrollo M, Ruiz-Canela M, Gea A, Martinez-Gonzalez M. Prevalence of obesity and diabetes in Spanish adults 1987-2012. Med Clin (Barc). 2017;148:250-6.

3. Franco M, Bilal U, Diez-Roux AV. Preventing noncommunicable diseases through structural changes in urban environments. J Epidemiol Community Health. 2015;69:509-11.

4. Story M, Kaphingst KM, Robinson-O'Brien R, Glanz K. Creating Healthy Food and Eating Environments: Policy and Environmental Approaches. Annu Rev Public Health. 2008;29:253-72.

5. Franco M, Bilal U, Díez J. Food Environment. Encycl Food Heal. 2016;4:22-26.

6. Diez J, Bilal U, Cebrecos A, Buczynski A, Lawrence RS, Glass T, et al. Understanding differences in the local food environment across countries: A case study in Madrid (Spain) and Baltimore (USA). Prev Med (Baltim). 2016;89:237-44.

7. Burgoine T, Lake AA, Stamp E, Alvanides S, Mathers JC, Adamson AJ. Changing foodscapes1980-2000, using the ASH30 Study. Appetite. 2009;53:157-65.

8. Da Silva R, Bach-Faig A, Raidó Quintana B, Buckland G, Vaz De Almeida MD, Serra-Majem L. Worldwide variation of adherence to the Mediterranean diet, in 1961-1965 and 2000-2003. Public Health Nutr. 2009;12:1676-84.

9. Black C, Moon G, Baird J. Dietary inequalities: What is the evidence for the effect of the neighbourhood food environment? Heal Place. 2014;27:229-42.

10. Ni Mhurchu C, Vandevijvere S, Waterlander W, Thornton LE, Kelly B, Cameron AJ, et al. Monitoring the availability of healthy and unhealthy foods and non-alcoholic beverages in community and consumer retail food environments globally. Obes Rev. 2013;14:108-19.

11. Bilal U, Díez J, Alfayate S, Gullón P, Del Cura I, Escobar F et al. Population cardiovascular health and urban environments: The Heart Healthy Hoods exploratory study in Madrid, Spain. BMC Med Res Methodol 2016;16. https://doi.org/10.1186/s12874-0160213-4.

12. Flavián C, Haberberg A, Polo Y. Food retailing strategies in the European union. A comparative analysis in the UK and Spain. J Retail Consum Serv. 2002;9:125-38.

13. Pettinger C, Holdsworth M, Gerber M. 'All under one roof?' Differences in food availability and shopping patterns in Southern France and Central England. Eur J Public Health. 2008;18:109-14.

14. Achón M, Serrano M, García-González Á, Alonso-Aperte E, Varela-Moreiras G Present food shopping habits in the Spanish adult population: A cross-sectional study. Nutrients 2017;9. https://doi.org/10.3390/nu9050508.

15. Díez J, Valiente R, Ramos C, García R, Gittelsohn J, Franco M. The mismatch between observational measures and residents' perspectives on the retail food environment: a mixed-methods approach in the Heart Healthy Hoods study. Public Health Nutr. 2017;20:2970 2979. https://doi.org/10.1017/S1368980017001604.

16. Bilal U, Jones-Smith J, Diez J, Lawrence RS, Celentano DD, Franco M Neighborhood social and economic change and retail 
food environment change in Madrid (Spain): The heart healthy hoods study. Heal Place 2018;51. https://doi.org/10.1016/j.hea lthplace.2018.03.004.

17. Hawkes C. Dietary implications of supermarket development: A global perspective. Dev Policy Rev. 2008;26:657-92.

18. Courtemanche C, Carden A. Supersizing supercenters? The impact of Walmart Supercenters on body mass index and obesity. J Urban Econ. 2011;69:165-81.

19. Machado PP, Claro RM, Martins APB, Costa JC, Levy RB. Is food store type associated with the consumption of ultra-processed food and drink products in Brazil? Public Health Nutr. 2018;21:201-9.

20. Bach-Faig A, Berry EM, Lairon D, Reguant J, Trichopoulou A, Dernini S, et al. Mediterranean diet pyramid today. Science and cultural updates. Public Health Nutr. 2011;14:2274-84.

21. Kamphuis CBM, Giskes K, de Bruijn GJ, Wendel-Vos W, Brug J, van Lenthe FJ. Environmental determinants of fruit and vegetable consumption among adults: a systematic review. $\mathrm{Br} \mathrm{J}$ Nutr. 2006;96:620-35.

22. Gullón P, Bilal U, Cebrecos A, Badland HM, Galán I, Franco M Intersection of neighborhood dynamics and socioeconomic status in small-area walkability: The Heart Healthy Hoods project. Int J Health Geogr 2017;16. https://doi.org/10.1186/s12942-017-00957.

23. Marquet $\mathrm{O}$, Miralles-Guasch $\mathrm{C}$. The Walkable city and the importance of the proximity environments for Barcelona's everyday mobility. Cities. 2015;42:258-66.

24. Glanz K, Sallis JF, Saelens BE, Frank LD. Nutrition Environment Measures Survey in Stores (NEMS-S). Development and Evaluation. Am J Prev Med. 2007;32:282-9.

25. Martins PA, Cremm EC, Leite FHM, Maron LR, Scagliusi FB, Oliveira MA. Validation of an adapted version of the nutrition environment measurement tool for stores (NEMS-S) in an Urban Area of Brazil. J Nutr Educ Behav. 2013;45:785-92. 